Monique Medeiros ${ }^{1}$

Adinor José Capellesso ${ }^{2}$

Ademir Antonio Cazella ${ }^{3}$

Geneviève Cortes 4

\title{
O surgimento de novos códigos sociotécnicos na construção de projetos desviantes de desenvolvimento rural
}

O sentido atribuído à agricultura vai sendo transformado pouco a pouco pela sociedade ao longo do tempo. Contudo, no mundo contemporâneo, a maioria dos consumidores que percorre os corredores dos supermercados em busca de alimentos não se dá conta de que os produtos ali dispostos referem-se a um conjunto de artefatos tecnológicos, resultantes de décadas ou mesmo séculos de pesquisa e desenvolvimento, a exemplo da seleção e melhoramento de plantas, voltados a encontrar materiais mais produtivos em distintos ambientes de cultivos (THOMPSON, 2009). Se tal percepção não é clara para os consumidores em geral, a tecnologia presente na produção de alimentos é algo habitualmente reconhecido por cientistas, agricultores e demais profissionais vinculados à área. Enquanto os consumidores veem o produto como resultado de uma "caixa preta", em que o interno lhes é desconhecido, esses peritos conhecem características específicas das

\footnotetext{
${ }^{1}$ Doutoranda do Programa de Pós-graduação em Agroecossistemas (PPGA) da Universidade Federal de Santa Catarina (UFSC) e pesquisadora do Laboratório de Estudos da Multifuncionalidade Agrícola e do Território (LEMATE). E-mail: mmedeiros@ymail.com.

${ }^{2}$ Doutor em Agroecossistemas na UFSC e pesquisador colaborador do Lemate. Professor de Produção Vegetal Agroecológica na Área de Recursos Naturais no Instituto Federal de Educação, Ciência e Tecnologia de Santa Catarina. E-mail: adinor.capellesso@ifsc.edu.br.

${ }^{3}$ Mestrado em Desenvolvimento, Agricultura e Sociedade pela Universidade Federal Rural do Rio de Janeiro (UFRRJ) e doutorado em Science de l'Homme et de la Société - Centre d'Etudes Supérieures d'Aménagement - Tours/França. Professor e coordenador da área de desenvolvimento rural da UFSC e do PPGA. Coordenador do LEMATE e membro do Observatório de Políticas Públicas para a Agricultura (OPPA) do Programa de PósGraduação de Ciências Sociais em Desenvolvimento, Agricultura e Sociedade (CPDA/UFRRJ). E-mail: aacazella@gmail.com.

${ }^{4}$ Professora Doutora na Universidade de Montpellier 3 - França e coordenadora do Projeto Franco-Brasileiro (CAPES-COFECUB) "Territórios, pobreza e políticas públicas: uma abordagem pela territorialização". E-mail: gc@hotmail.com.
} 
espécies, cultivares e tecnologias com vistas a elaborar distintos sistemas de exploração agrícola.

Para grande parte desses cientistas, agricultores, engenheiros agrônomos e técnicos agrícolas, dentre outros, seu entendimento de tecnologia moderna está fortemente atrelada à ideia de inovação, vinculada à aplicação de produtos químicos na forma de fertilizantes e agrotóxicos a organismos geneticamente modificados ${ }^{5}$ ou à mecanização das atividades para reduzir o emprego de trabalho humano e aumentar a escala de produção. Mesmo esses profissionais têm dificuldades em entender como tecnologia aquelas que já estão imersas em seu cotidiano há muito tempo, como o simples ato de lançar uma semente ao solo (THOMPSON, 2009). A naturalização de tais práticas tende a reduzir as possibilidades de observação e, consequentemente, de intervenção por parte desses profissionais.

Segundo Thompson (2009), as atividades agrícolas que nascem do vínculo entre inovação e tecnologia correspondem somente a uma face dos diversos domínios de aplicação tecnológica na agricultura. Para além de ferramentas (foices, tratores e colheitadeiras, dentre outras), insumos (como fertilizante, semente e agrotóxicos) e sistemas de cultivo, o autor destaca que a base tecnológica inclui modos peculiares de organização de grupos de agricultores, elementos geralmente não associados à ideia comum de tecnologia agrícola. Essa complexidade de domínios e de configurações tecnológicas é o que o conduz a afirmar que a agricultura é uma atividade inerentemente ambígua.

A ambiguidade se dá na medida em que as escolhas que levam à adesão de determinados tipos de agricultura podem exercer influências tanto positivas quanto negativas para além do espaço rural. Essas escolhas estão atreladas diretamente a modelos de desenvolvimento que, quando operacionalizados, são capazes de elevar ou reduzir os custos com recursos humanos e materiais (BUNGE, 1985). Como exemplo, artefatos e processos produtivos inerentemente agropecuários foram gradativamente apropriados pelas indústrias e convertidos em insumos, o que geralmente é entendido como expressão da modernização tecnológica (GOODMAN et. al., 1990). Outro elemento clássico é a busca pela redução na necessidade de mão de obra para produzir quantidade equivalente de alimento.

\footnotetext{
${ }^{5}$ Os organismos geneticamente modificados, ou transgênicos, são aqueles que passaram por processos de alteração do código genético por meio da introdução de uma ou mais sequências de genes provenientes de outra espécie mediante a aplicação de técnicas vinculadas à engenharia genética. Sua produção é justificada com o argumento de que os genes introduzidos, não pertencentes ao genoma original da espécie modificada, poderão conferir novas características, como resistências a determinados herbicidas, a produção de substâncias que controlam insetos, maior resistência a deficits hídricos, entre outras (MARICONDA; RAMOS, 2003).
} 
O fato de distintas sociedades adotarem, cada vez mais, tecnologias concebidas em outros países, os quais possuem estilos próprios de desenvolvimento, influencia diretamente na acentuação de contradições. Muitas vezes, essas tecnologias são incorporadas em outros contextos, nos quais as pessoas desconhecem amplamente suas bases científicas (HERRERA, 1978). Embora sua origem seja voltada ao controle do processo produtivo, geralmente não se tem o controle sobre os efeitos da aplicação dessas tecnologias na sociedade. A reflexão acerca das consequências geradas pelas transferências de tecnologias é fator elementar para que as contradições cedam lugar à construção de processos de desenvolvimento sustentáveis no tempo e adaptados às necessidades locais (BUNGE, 1985; WINNER, 1995; CUPANI, 2013).

De acordo com Herrera (1978), embora as experiências exógenas possam inspirar a incorporação de inovações pontuais nas sociedades, é extremamente importante que as localidades (re)construam suas próprias tecnologias. Essa é uma condição sine qua non para a adequação das tecnologias aos objetivos vinculados a contextos sociais específicos e, consequentemente, para o surgimento de processos criativos autênticos. Corroborando esse pensamento e direcionado a análise para o meio rural, este artigo objetiva oferecer uma base teórica para a compreensão de novos códigos sociotécnicos que buscam valorizar as especificidades locais. Ao evidenciar as formas variadas de compreensão e aplicação das tecnologias segundo os distintos interesses que as guiam, este estudo salienta a importância da diversidade sociocultural para o fortalecimento de projetos heterogêneos de desenvolvimento rural mais preocupados com a sustentabilidades ambiental, socioeconômica e cultural.

A análise aqui apresentada articula duas abordagens, a saber: a Construção Social da Tecnologia e a Perspectiva Orientada ao Ator. Enquanto a primeira alicerça a compreensão dos processos de mudança tecnológica, que não são estritamente sociais ou puramente tecnológicos, mas sociais e tecnológicos simultaneamente (PINCH; BIJKER, 2008), a segunda ressalta a importância dos atores sociais na construção de estratégias no enfrentamento das situações problemáticas que estão sob diversificadas formas de coerção em seu cotidiano (LONG; PLOEG, 1994).

$\mathrm{O}$ artigo está dividido em cinco tópicos. O primeiro busca evidenciar que a tecnologia não é somente um conjunto ordenado de técnicas, mas um fenômeno que transforma constantemente o contexto social ao qual está imbricado. $\mathrm{O}$ segundo se concentra em relacionar a diversidade de estilos de agricultura e suas interfaces com as tecnologias. O terceiro apresenta a Perspectiva Orientada ao Ator, mais especificamente a ideia de construção de projetos heterogêneos a fim de evidenciar que tais projetos apontam para a elaboração de um novo código sociotécnico na agricultura. O quarto aproxima essa perspectiva teórica da Construção 
Social da Tecnologia, uma abordagem que procura investigar e compreender a coconstrução da tecnologia e da sociedade. Por fim, o quinto tópico expõe as considerações finais acerca do tema apresentado, salientando a importância da diversidade de estilos de agricultura na construção de projetos heterogêneos de desenvolvimento rural, que se sustentem dos pontos de vista econômico, sociocultural e ambiental no decorrer do tempo.

\section{Tecnologia: um fenômeno social}

A técnica é um meio utilizado com intuito de alcançar determinados fins. A racionalidade de fins é tanto expressão de processos técnicos quanto dos interesses que os movem (BRÜSEKE, 2002). Produzir e viver tecnicamente se apresentam como capacidades intrínsecas do ser humano. Ainda que a habilidade técnica acompanhe a existência humana desde seus primórdios é possível distinguir a técnica pré-científica da tecnologia. Ou seja, da técnica alicerçada na ciência (BUNGE, 1985). A intervenção da ciência na produção de artefatos é vista como geradora de uma importante diferença em relação à técnica tradicional, baseada no conhecimento empírico do mundo, visto que a tecnologia é resultante da aplicação do saber obtido em processos sistemáticos (CUPANI, 2013).

Para além das manifestações das capacidades humanas de fazer coisas, o que articula formas antigas e modernas é o fato de que toda a produção, técnica ou tecnológica, é a manifestação de um saber fazer. A capacidade de fazer significa produzir diferença por meio de escolhas racionais que orientam o agir, ou de conduzir conscientemente a própria vida em vez de viver de modo unicamente instintivo. Embora a racionalidade sempre seja limitada por falta de informações e conhecimentos, ou mesmo pela incapacidade de prever com exatidão e precisão processos multifatoriais, a produção técnica ou tecnológica oferece uma direção lógica para quem a adota.

De acordo com Heidegger (1999), para que o sentido originalmente atribuído à expressão techne possa ser verdadeiramente aprendido, bem como para que a técnica posterior ou tecnologia moderna seja convenientemente compreendida, é necessário que esse termo seja pensado no seu sentido grego. Assim, o autor sugere a interpretação do significado de techne como "conhecer-se no ato de produzir" (HEIDEGGER, 1999, p. 21). Nesse caso, a técnica se diferencia da tecnologia moderna pelo fato dessa última distanciar a geração do conhecimento do ato de produzir. Olhar para a tecnologia com base na dualidade "conhecer/produzir" abre possibilidades de enxergá-la para além de algo exterior e exclusivamente instrumental, pois incorpora a maneira pela qual o humano se apropria, a incorpora no meio ao qual está inserido (BRÜSEKE, 2002) e, consequentemente, compreende a si mesmo. 
A produção e o uso de artefatos implicam técnicas e maneiras específicas dos humanos conhecerem e relacionarem-se com o mundo material. Embora essas maneiras incorporem o saber científico, ainda assim conservam características próprias. Devido à particularidade desse conhecer e relacionar-se com o mundo material, o que denominamos tecnologia se apresenta como uma realidade multifacetada, não apenas em forma de objetos e conjuntos de objetos, mas também como sistemas, processos, modos de proceder e pensar (CUPANI, 2013).

Transcendendo a racionalidade de fins, que não deixa de existir, ao menos indiretamente, a ciência básica vem criando cada vez mais meios que buscam fins tecnológicos a posteriori. ${ }^{6}$ A tecnologia moderna é altamente contingente, o que influencia a sociedade a buscar fins simplesmente pelo fato de possuir um meio (BRÜSEKE, 2002). Nesse caso, a ilusão de que a tecnologia oferecerá a solução para todos os problemas converte o desenvolvimento tecnológico em um fim ${ }^{7}$.

A possibilidade de certas tecnologias serem concebidas como meio sem um fim premeditado não significa que sua aplicação seja desprovida de valores. Pelo contrário, o próprio fato de o desenvolvimento tecnológico assumir importância central constitui-se em um valor, o qual pode ser compatível ou contrário às normas vigentes em distintos modos de vida. Quando aplicada na agricultura, a tecnologia é guiada por determinados estilos de trabalho e, consequentemente, por perspectivas e projetos de desenvolvimento rural que não são necessariamente compatíveis com as formas de vida e processos naturais locais. Em sentido oposto, a concepção hegemônica de desenvolvimento rural está atrelada à ideia de controle e padronização dos sistemas de produção agropecuária.

Não por acaso, a agropecuária vem se tornando cada vez mais dependente da introdução de instrumentos tecnológicos que, por mais que otimizem a produtividade, têm gerado resultados econômicos marginais decrescentes em relação ao aumento de sua utilização. Ou seja, um crescente squeeze (aperto) entre o valor da produção agropecuária e seus custos (CAPELESSO et al., 2016; PLOEG, 2006). Em geral, a tecnologia

\footnotetext{
${ }^{6}$ De acordo com Bunge (1985), ao passo que a ciência básica deseja obter o saber pelo seu valor intrínseco e a tecnologia almeja a solução de problemas práticos mediante recursos científicos, a ciência aplicada representa uma zona intermediária entre as duas. Apesar de seu desenvolvimento ter por objetivo a construção de conhecimento, tal objetivo tem por base as projeções práticas desse conhecimento. Cupani (2013), buscando uma maior elucidação acerca dessas distinções, exemplifica da seguinte maneira: uma ciência básica, como a sociologia, difere de uma ciência aplicada, como a sociologia do desenvolvimento, que, por sua vez, pode fundamentar uma tecnologia, como a da planificação do desenvolvimento.

${ }^{7}$ A tecnologia também pode ser vista como um meio para alcançar o fim econômico de quem a gerou ou a transformou em produto de mercado. Contudo, mesmo nesses casos, a sua aplicação sempre é justificada por outros fins.
} 
tem sido frequentemente empregada no espaço rural priorizando os valores econômicos e políticos. Ao desconsiderar as outras dimensões, ou mesmo pela dificuldade de efetivar os anseios prioritários de parcela das populações locais, consequências desastrosas nas dimensões socioculturais e ambientais vêm sendo geradas.

Os pacotes tecnológicos difundidos no processo de modernização da agricultura foram formulados em centros de pesquisa cujas prioridades eram - e ainda são - definidas sob a influência de interesses das corporações e do setor agroindustrial, as quais ficam com a maior parte dos resultados de sua aplicação nos sistemas produtivos. Nesse contexto, privilegiam-se os métodos e critérios de validação que se restringem a situações de laboratório e se voltam à busca incessante por maiores produtividades e maior acúmulo de renda.

Esse processo é apontado, geralmente, como resultado da chamada "Revolução Verde", um conjunto de tecnologias difundidas de forma articulada como pacotes a partir do final da década de 1950 e início da década de 1960. Entre as explicações, esse processo teria origem na necessidade de as indústrias de armamento dos países vencedores da $2^{\mathrm{a}}$ Guerra Mundial manterem a lucratividade obtida durante sua aplicação bélica. Como esse argumento não teria apelo social e político, sua aplicação era justificada pela necessidade de eliminar o problema da fome no mundo. Esse propósito justificaria a modernização com foco no aumento da produção e da produtividade agrícola por meio do uso crescente de insumos modernos, com destaque para variedades vegetais e espécies animais de alta produtividade, que respondem a altas doses de fertilizantes químicos, agrotóxicos e alimentação concentrada, associadas à monocultura para viabilizar a intensificação da mecanização.

No caso brasileiro, a difusão dessas tecnologias foi fomentada pelo Estado por meio da criação de políticas públicas voltadas a estimular sua adoção entre os agricultores. Pode-se citar como parte dessas estratégias o crédito subsidiado, atrelado à aquisição de insumos e máquinas, a criação de órgãos de pesquisas e extensão para dar suporte ao modelo produtivista e o treinamento de professores, em especial, das faculdades e cursos técnicos especializados nas ciências agrárias (DELGADO, 1985).

A busca de produtividade e eficiência pela combinação do aumento de escala e aplicação de tecnologias modernas balizadas pelas "inovadoras" ciências e tecnologias passou a ser fator, aparentemente, primordial e indispensável para a parcela dos agricultores integrados às cadeias produtivas de commodities. Nesses casos, a diversidade foi cedendo espaço à crença de que a especialização tecnológica seria a forma mais eficiente $\mathrm{e}$ eficaz de produção material e de organização social. Um dos resultados perversos desse processo foi a intensificação das desigualdades sociais e regionais no país. Essa associação de fatores, ao mesmo tempo em que 
não resolveu o problema da fome no mundo, favoreceu um número diminuto de produtores rurais, restringindo as estratégias tradicionais de reprodução social da ampla maioria dos agricultores familiares.

Porém, ao longo do século XX surgiram evidências de que a especialização e a racionalização não são suficientes para responder às necessidades diversas dos processos de desenvolvimento rural. Dentre os reflexos dessas contradições, nos anos recentes constata-se um aumento expressivo de criação de estratégias de sobrevivência no espaço rural com foco em novas formas de relação entre os agricultores e as tecnologias.

\section{Os estilos de agricultura e as interfaces com o contexto sociotécnico}

A mutualidade de influências entre distintas lógicas de desenvolvimento no rural, notoriamente, não é um processo recente. As formas dessas inferências são transformadas dinamicamente com o passar dos anos, de acordo com interesses e necessidades dos agricultores e dos demais atores associados, o que gera distintas consequências. Wanderley (2003) discute as transformações provocadas pela inserção do trator nas atividades agrícolas no início do Século XX. Tal fato introduziu uma noção de tempo abstrato, antes vinculada exclusivamente ao mundo industrial, que modificou a noção que os agricultores tinham do tempo associado às vicissitudes da natureza e ao calendário agrícola.

Difundido fortemente em meados de 1920, o trator foi uma das materializações de um projeto de intensiva mecanização da agricultura nos Estados Unidos (VIAN; JUNIOR, 2010). Assim como ocorreria mais tarde em outras partes do mundo, sua adoção foi apoiada pelo governo americano por meio de um conjunto de programas agrícolas, projeto que teve como intuito a modernização da agricultura com vistas a elevar a produtividade e os lucros pelo emprego de tecnologias e mão de obra especializada.

O estudo realizado por Mendras intitulado "La fin des paysants" (O fim dos camponeses), publicado no ano de 1984, ilustra que a utilização de máquinas e das demais tecnologias do processo de modernização agrícola impulsionara a construção de um modo industrial de fazer agricultura. Esse estudo aborda a crise do campesinato na França a partir dos anos 1960 e demonstra como a introdução do milho híbrido, de origem americana, modificou profundamente as formas de produção camponesas presentes no meio rural do país até o pós-guerra. Para esse autor, ainda que o manejo da nova variedade, aparentemente, não diferisse em muito daquele vinculado à variedade local antes utilizada, sua generalização culminou em metamorfoses em todas as relações sociais que estruturavam o mundo rural tradicional.

Com o desencadeamento de tais transformações, o exercício da atividade agrícola passou a exigir, cada vez mais, o domínio de 
conhecimentos técnicos específicos para o desenvolvimento do trabalho com plantas, animais e máquinas, bem como o controle de sua gestão por meio de uma nova forma de enxergar a economia (WANDERLEY, 2003). A isso se associa a dimensão dos pacotes tecnológicos da Revolução Verde, em que o uso de uma tecnologia pontual demanda outra complementar para tornar a primeira mais eficiente. E assim, concomitante ao advento de tantas outras novas tecnologias, toda a estrutura da sociedade camponesa tradicional foi sendo modificada de maneira significativa.

Se, por um lado, as formas tradicionais de agricultura se reconfiguraram frente ao processo de modernização agrícola, integrandose aos mercados e respondendo às suas exigências, por outro, ela continuou abrangendo agricultores cujo projeto de vida se manteve guiado por lógicas familiares. $\mathrm{O}$ fato de esses agricultores permanecerem familiares não é insignificante. Pelo contrário, é a expressão de reconhecimento de que a lógica de origem camponesa representa uma importante alternativa para se adaptar às mudanças de um sistema capitalista em constante mudança (LAMARCHE, 1993; PLOEG, 2006).

No Brasil, essas reconfigurações ampliaram a diversidade de formas de agricultura, as quais têm bases na riqueza do tecido social de inúmeras regiões rurais e na construção de distintas identidades sociais que foram sendo suscitadas pelas transformações do meio rural. Como resultado dessa multiplicidade, evidencia-se um aumento expressivo de estratégias de sobrevivência no espaço rural com foco em novas atividades produtivas e fontes de renda (NIERDELE; SCHNEIDER, 2008).

A variedade de estratégias a partir das quais atores sociais do campo produzem e ordenam os recursos e tecnologias disponíveis não é sinônimo de ineficiência e ineficácia no uso de recursos e na organização societária, como geralmente a modernidade e a crescente racionalização das sociedades levaram a crer (SCHNEIDER, 2010). Ao invés disso, tal diversidade passa a ser entendida como uma das principais características que sustentam a agricultura contemporânea mundial.

Segundo Ploeg (2008), por mais desordenada que pareça, essa diversidade que compõe a agricultura mundial é resultante de trajetórias de desenvolvimento, mutuamente contrastantes, porém interrelacionadas, as quais interagem com uma determinada segmentação da agricultura. Tais segmentações podem ser conceituadas, ainda que de forma sinóptica, por meio de três grupos distintos que estão em constante interação.

O primeiro grupo é constituído pela agricultura capitalista ou corporativa de grande escala. Esse setor da agricultura engloba uma rede bastante densa de empresas agrícolas de grande mobilidade, as quais utilizam mão de obra, essencialmente ou quase exclusivamente, de trabalhadores assalariados. Esse grupo abrange cada vez mais segmentos 
de mercados agrícolas e alimentares de commodities, e sua produção é voltada para a maximização do lucro. Os processos de produção desenvolvidos por esse setor da agricultura são altamente dependentes do que se denomina high tech (alta tecnologia) (PLOEG, 2008).

O segundo grupo refere-se à agricultura do tipo empresarial, que, apesar da possibilidade de ter base familiar, se diferencia da camponesa devido à elevada integração aos mercados, bem como sua forte relação com pacotes tecnológicos. Além do elevado uso de insumos, esse tipo de agricultura articula estabelecimentos rurais com grandes empresas de processamento e comercialização de commodities que, cada vez mais, operam em escala mundial centralizadas em tecnologias high tech e na especialização da mão de obra. Além disso, ainda que não exclusivamente, é dependente do capital financeiro e industrial, quer seja na forma de crédito, insumos industriais ou maquinários. Nesse caso, a operacionalização de programas governamentais de "modernização" da agricultura é um fator que influencia a emergência e a manutenção de formas de agricultura empresarial (PLOEG, 2008).

O terceiro grupo corresponde à agricultura camponesa, a qual se baseia fundamentalmente em mão de obra familiar e na coprodução, uma forma de reconexão da sociedade com a natureza por meio do exercício de uma agricultura mais independente da indústria e mais vinculada à interação e transformação recíproca do social e do natural. As principais características desse tipo de agricultura são a economia de recursos escassos, possibilitada, principalmente, por meio da construção e adaptação de tecnologias de fácil operacionalização; a multifuncionalidade; ${ }^{8}$ a natureza da mão de obra fundamentalmente familiar ou mobilizada dentro da comunidade rural por meio de relações de reciprocidade; e o destino da produção orientada não somente para o mercado, mas também para a reprodução da unidade agrícola e da família (PLOEG, 2008).

Segundo Ploeg (2008), a diferença central entre esses três grupos reside na escala em que são aplicados e nas relações que os agricultores estabelecem com a esfera tecnológica. A agricultura camponesa representa unidades de produção pequenas, centradas na família, com pouco uso de tecnologias externas (insumos e máquinas) e com certo distanciamento dos complexos agroindustriais, o que a torna secundária sob a perspectiva do regime hegemônico de produção. No lado oposto, encontra-se a agricultura capitalista, com elevado uso de insumos, grande

\footnotetext{
8 Trata-se da percepção das inúmeras funções desempenhadas pela agricultura e pelos agricultores familiares nas dinâmicas de desenvolvimento, as quais não se restringem à produção de alimentos e fibras. Abrangem desde a conservação dos recursos naturais e da agrobiodiversidade, até a coesão sociocultural de determinados territórios e a construção e manutenção da paisagem rural (CAZELLA et al., 2009).
} 
escala, orientada para a produção de commodities. A situação intermediária mescla trabalho familiar com elevado emprego de tecnologias e é representada pela agricultura empresarial, a qual compreende tanto unidades produtivas pequenas quanto grandes.

Apesar das diferenças, existem interseções entre esses três grupos, as quais se dão por sobreposições e ambiguidades, que fazem com que seus limites sejam ultrapassados por movimentos dinâmicos de ida e vinda que se constroem no decorrer do tempo (PLOEG, 2008). Segundo Wanderley (2003), ao discutir uma tipologia de agricultores familiares semelhante à analisada aqui, constata-se que, para além de estagnações ou passagens irreversíveis e absolutas de um grupo para o outro, há simultaneamente pontos de ruptura e elementos de continuidade. Enquanto a agricultura camponesa se aproxima mais de um modelo de desenvolvimento focado na construção e reprodução de circuitos curtos e descentralizados de comercialização, que articulam produção e consumo de alimentos e, de forma mais geral, a agricultura e a sociedade regional, a agricultura capitalista e a empresarial estão mais conectadas a um modelo voltado a atender as necessidades de consumo mundial, por meio de empresas de processamento e comercialização de alimentos de grande escala (LONG; PLOEG, 1994).

O modelo de desenvolvimento camponês caracteriza-se pela continuidade de técnicas e costumes utilizados no passado, por vezes, adaptados às necessidades do contexto atual do campo. Dotados de perícia artesanal e prática, esses agricultores constroem tecnologias diferenciadas baseadas em suas habilidades, valorizando as diversidades sociais e técnicas (PLOEG, 2008). Já o segundo modelo é constituído pelas duas outras categorias de agricultores e se personifica nas distintas expressões do agronegócio, a exemplo de grandes varejistas, mecanismos estatais, leis, modelos científicos e tecnologias. Esse modelo é denominado por Ploeg (2008, p.20) como "Império".

Entendido como um modo de ordenamento que tende a se tornar dominante, o Império constitui um conjunto de regras compreendidas no complexo coerente de conhecimento científico, práticas de engenharia, tecnologias do processo produtivo e de formas de definir problemas. Por conseguinte, não se trata apenas de "fenômeno emergente" e internamente diferenciado, pois consiste no "fortalecimento mútuo e intrincado de uma grande variedade de elementos, relações, interesses e modelos" (PLOEG, 2008, p.20).

De acordo com Ploeg (2008), o Império impulsiona e reproduz as agriculturas capitalista e empresarial e se caracteriza-se por uma produção altamente especializada, desenhos técnicos normativos e produção totalmente orientada ao e pelo mercado global. Como resultado, os agricultores acabam por depender ativamente dos mercados 
competitivos e, especialmente, do mercado financeiro. A agricultura camponesa também é submetida ao Império, mas por meio de outros mecanismos. Contudo, esse tipo de agricultura apresenta certa resistência ao Império, por meio de formas camufladas de escapar ou reduzir as pressões.

As consequências dessas influências dinâmicas têm sido verificadas como um dos fatores de reconfiguração da complexidade dos espaços rurais, o qual se traduz em um mosaico social, econômico e cultural, que acompanha uma crescente diversificação de atividades produtivas, fontes de renda e formas de se relacionar com a esfera tecnológica. Esse ambiente pode conduzir à configuração de estilos de agricultura distintos, compartilhados por um grande grupo de agricultores (PLOEG, 2011) e voltados a projetos que internalizam relações características do modelo de agricultura prevalecente, mas que conservam algumas características camponesas. Esses estilos se aproximam tanto do que Ploeg (2006) denomina de uma "forma empresarial de agricultura familiar" quanto do que Lamarche (1998) conceitua como "agricultura familiar moderna" 9 .

A adjacência desses conceitos se evidencia no fato de que ambos (empresarial familiar e familiar moderna) estão vinculados a unidades de produção menos intensivas do ponto de vista das lógicas produtivas e mais autônomas do que as formas empresariais puras em relação ao mercado global. Nessas unidades, a produção para autoconsumo e, consequentemente, a autonomia alimentar são fatores parcialmente conservados. Esse estilo de agricultura funciona com traços da agricultura camponesa, porém, com mais acesso a tecnologias e aos mercados.

As diversas estratégias de resistência desse tipo de agricultura estão relacionadas com mudanças nos processos de trabalho, investimentos de capital, ciclo produtivo, reprodução do grupo familiar e o universo de relações sociais prioritárias, o que reflete em aumento ou diminuição do grau de dependência de determinadas tecnologias e mercados. Nas pesquisas de Long e Ploeg (1994), em especial, as estratégias assumem uma posição central, pois permitem interpretar a mudança social a partir das disputas e negociações entre atores que possuem interesses distintos e não raramente conflitantes. Com o intuito de compreender as interfaces, pontos de intersecção ou de confronto entre as estratégias ou projetos dos distintos atores, esses autores sistematizaram a Perspectiva Orientada ao Ator (POA). Os aportes dessa perspectiva têm se mostrado úteis no entendimento de como uma nova tecnologia reflete diretamente no projeto dos atores, sendo transformada e ressignificada, se tornando um

\footnotetext{
${ }_{9}^{9}$ Segundo Lamarche (1998), a agricultura familiar moderna é caracterizada por uma limitada integração com os mercados e uma significativa independência alimentar. O estudo comparativo internacional coordenado por esse autor revela que o Brasil é o país com maior incidência da agricultura familiar moderna, detendo cerca de $50 \%$ das unidades pesquisadas.
} 
dos fatores que constitui a diversidade produtiva e a heterogeneidade social.

\section{Articulando agências na concepção de um projeto heterogêneo de desenvolvimento rural}

A Perspectiva Orientada ao Ator consiste em uma abordagem dos processos sociais, econômicos e culturais que busca romper com as perspectivas teóricas estruturalistas e com o individualismo metodológico, os quais, segundo Long e Ploeg (1994), adotam visões deterministas e lineares da mudança social. Essa perspectiva compreende que os padrões diferenciais que emergem são, em parte, criados pelos próprios atores, os quais são vistos como participantes ativos que processam informações e constroem estratégias nas suas relações com outros atores locais, assim como com instituições e pessoas externas (LONG; PLOEG, 1994).

Com intuito de aprofundar a compreensão sobre a participação e atuação dos atores sociais, uma das noções centrais da POA é a "agência". Em termos gerais, essa noção atribui ao ator, individual ou grupo social, a capacidade de processar a experiência social e traçar caminhos alternativos para o enfrentamento das situações problemas que estão sob diversificadas formas de coerção (LONG; PLOEG, 1994). Tal capacidade requer organização, não sendo um resultado simples de certas habilidades cognitivas, poderes persuasivos ou formas de carisma que um indivíduo possa ter. Para além das contingências globais, a agência e o poder a ela atrelado dependem da emergência de uma rede de atores que se envolvem com distintas intensidades em projetos e práticas de outros indivíduos.

A agência efetiva está diretamente relacionada à criação e à manipulação estratégica de uma rede de relações sociais e concentração de itens específicos, como reivindicações, ordens, bens, artefatos e informação em pontos fundamentais de interação. Afinal, as precondições para o surgimento da agência são as interações, interfaces e transformações entre os "mundos", os "projetos" e os repertórios culturais dos atores em "arenas" específicas e localizadas (LONG, 2001). A arena é compreendida como situação social na qual os atores confrontamse, mobilizam as relações sociais e utilizam discursos com a finalidade de alcançar objetivos específicos. Nesses termos, trata-se de uma noção importante a ser aplicada na análise de processos de desenvolvimento, principalmente nas intervenções que ocorrem em um conjunto de arenas entrelaçadas (LONG, 2001).

Inspirada nas teorias formuladas por Bourdieu (1981), a POA se fundamenta na ideia de que, nos processos desencadeados nas arenas, os atores utilizam seus "domínios" particulares para apoiar seus interesses e 
disposições. Os "domínios" são áreas da vida social que estão organizadas por referência a um núcleo central. São espaços que possuem regras, normas e valores que implicam um grau de compromisso social e representam valores compartilhados pelos atores sociais. Como exemplos, pode-se pensar nos domínios da família, do mercado, do Estado, de grupos, da produção e do consumo. Em um complexo de arenas entrelaçadas, os atores sociais exercem sua capacidade de agência com o amparo de seus domínios particulares. Essa condição lhes permite construir projetos comuns, os quais podem ser entendidos como formas de articulação de seus próprios projetos de vida com os de outros atores sociais (LONG, 2001).

A POA parte do pressuposto que distintos agricultores, ou categorias de agricultores, definem e operacionalizam seus objetivos e práticas de gerenciamento relacionados à agricultura com base em diferentes critérios, interesses, experiências e perspectivas. Isso faz com que esses agricultores desenvolvam, ao longo do tempo, projetos e práticas específicas para a organização de suas atividades no campo. Esses projetos, aqui denominados 'heterogêneos', podem ser entendidos, de certo modo, como respostas a outros projetos formulados, por exemplo, por agências estatais ou empresas ligadas ao agronegócio (LONG, 2001).

Na construção dos projetos heterogêneos, os atores renunciam certas iniciativas individuais com vistas à construção coletiva de estratégias. Entretanto, ainda que haja um único projeto, esse guarda heterogeneidades internas e consensos provisórios (MEDEIROS, 2011). Os novos projetos de desenvolvimento tendem a trazer alternativas sociotécnicas inovadoras. Contudo, ao invés de serem recebidas passivamente pelos agricultores, essas alternativas tendem a ser transformadas e adaptadas a seus estilos de agricultura. Elas podem estar relacionadas à incorporação ao cotidiano de novos artefatos e/ou combinações de recursos e procedimentos tecnológicos provenientes de diferentes campos do conhecimento.

\section{A construção social de novos códigos sociotécnicos}

As tecnologias desempenham um papel central nos processos de mudança social. Elas demarcam posições e condutas da sociedade, condicionam estruturas de distribuição social, custos de produção, acesso a bens e serviços, geram problemas sociais e ambientais e facilitam ou dificultam sua resolução (THOMAS, 2009). Essas percepções foram aprofundadas e melhor problematizadas graças a um conjunto de estudos, principalmente, oriundos da sociologia e da filosofia, que procuraram investigar e compreender melhor a co-construção da tecnologia. 
Desenvolvida por Trevor Pinch e Wiebe Bijker (1987), a abordagem da Construção Social da Tecnologia assume que as mudanças tecnológicas se encontram determinadas por processos sociais mais do que por qualquer "lógica tecnológica" interna. Esses autores argumentam que os critérios da funcionalidade tecnológica possuem uma origem social e, desse modo, colocam em questionamento as explicações "ingênuas" do êxito dos artefatos técnicos segundo as quais o critério de escolha pela adoção de novos artefatos técnicos se deve exclusivamente a um melhor desempenho funcional. Até porque a funcionalidade gera diferentes resultados em distintos contextos nos quais é aplicada.

Para além de uma crítica às explicações comuns da razão de certas tecnologias serem mais exitosas do que outras, essa nova perspectiva oferece uma teoria acerca das mudanças tecnológicas (BRUUN; HUKKINEN, 2008). Pinch e Bijker (1987) evidenciaram processos que articulam a constituição de problemas pela sociedade, as escolhas tecnológicas para a mudança e melhoria de situações problemáticas e os caminhos traçados pela sociedade para o seu desenvolvimento. O problema é definido como tal somente quando há um "grupo social relevante" que assim o classifica. Essa abordagem compreende como grupos sociais relevantes as instituições e organizações, assim como os grupos de indivíduos organizados ou não. De acordo com os autores, para que um grupo social relevante seja assim identificado, todos os seus membros devem compartilhar um conjunto similar de significados vinculados a um artefato específico.

A proximidade entre o conceito de grupo social relevante e a noção de agência, um dos pilares da Perspectiva Orientada ao Ator, é evidente. Em ambas é necessário que os indivíduos, além de partilharem percepções acerca dos problemas que os rodeiam, busquem coletivamente caminhos que os levem à sua superação (PINCH; BIJKER, 2008). Segundo Long e Ploeg (1994), o enfrentamento das situações problemáticas é possibilitado devido à mobilização da agência dos atores que constituem esses grupos sociais. Embora existam limitações decorrentes da estrutura sociocultural, a agência é expressa pela capacidade de criação e manipulação estratégica desses grupos, nos quais, entendimentos, reivindicações, bens e informações são fatores decisórios nas escolhas tecnológicas que norteiam os caminhos a serem trilhados.

Essas escolhas são reflexos diretos da interpretação que os atores sociais constroem coletivamente dos artefatos (PINCH; BIJKER, 2008). Os artefatos podem ser interpretados pelos atores de maneira muito diferentes, visto que possuem "flexibilidade interpretativa" (BIJKER, 1995). Essa interpretação depende do tipo de problemas para os quais uma ou mais tecnologias são consideradas uma solução. Diferentes grupos de pessoas definem problemas relevantes de formas distintas. 
Tais diferenças tornam-se particularmente visíveis na ocorrência de controvérsias tecnológicas (BRUUN; HUKKINEN, 2008). Ainda que, por vezes, as trajetórias diferentes sejam alinhadas e sigam por direções similares, criando estabilidade e resiliência, em outras as trajetórias podem divergir e resultar em desajustes e tensões. Afinal, o surgimento da agência é desencadeado pelas interações, interfaces e transformações entre as visões de mundo, os interesses e os repertórios culturais dos atores nos grupos sociais (LONG, 2001). Nesse campo de disputa, ganha importância as diferenças de poder e os distintos tipos de capital portados pelos atores e suas organizações, pois geralmente há conflitos e disputas (BOURDIEU, 1989).

Quando as atividades desses grupos e suas trajetórias seguem para diferentes direções, ocorrem desalinhamentos e instabilidades nos marcos tecnológicos. Bijker (1995, p. 276) tem utilizado o termo "marco tecnológico" (technological frame) para descrever como os grupos sociais relevantes interpretam o artefato em si. De acordo com o autor, por marco tecnológico pode-se entender um conjunto de elementos sociais que direciona as interações que ocorrem dentro dos grupos sociais e os conduz à atribuição de sentido aos artefatos técnicos.

É possível que cada um dos grupos sociais relevantes apresente expectativas dessemelhantes sobre uma tecnologia e atribua a ela sentidos significativamente diferentes. A divergência de opiniões acerca da forma final e dos resultados esperados pela utilização do artefato acaba sendo problematizada por meio de negociações nas arenas sociais, que podem vir a gerar conflitos entre os grupos. Nesse processo de negociação, algumas ideias iniciais permanecem, enquanto outras desaparecem, são transformadas ou incorporadas.

Esse processo está diretamente relacionado ao fato de que alguns atores têm uma alta inclusão no marco tecnológico ao qual pertencem, estando alinhados com o código social dessa estrutura e ocupando posição central nas decisões, enquanto que outros atores não possuem um vínculo tão forte com a estrutura na qual estão inseridos, ocupando uma posição marginal. Apesar dessas diferenças, a inclusão em um dado marco tecnológico não é algo binário. Em vez de ser central ou marginal, um membro de um grupo social pode ter distintos graus de inclusão no marco tecnológico, e essas gradações podem variar de acordo com as situações sociais nas quais estão envolvidos (BIJKER, 2008).

A compreensão acerca dos gradientes de inclusão dos atores sociais nos marcos tecnológicos pode ser aprofundada incorporando na análise a noção - tributária da POA - de "arena social". A maior ou menor inclusão dos indivíduos em um marco tecnológico está vinculada às relações de poder que se dão nas arenas sociais que o delineiam. Nessas arenas, os atores confrontam interesses, mobilizam as relações sociais e utilizam 
discursos com a finalidade de justificar objetivos específicos (LONG, 2001).

As opiniões inicialmente apresentadas nas arenas sociais vão sendo reavaliadas e negociadas pelos grupos até que tendam a uma "estabilização". Posterior a esse estágio de convergência de determinadas opiniões, o processo de construção do artefato começa a caminhar para um "fechamento" da situação de conflito (FERTRIN, 2008). De acordo com Pinch e Bijker (2008) podem existir dois mecanismos de fechamento diferentes para a situação: o fechamento por redefinição do problema e a retórica do fechamento.

O primeiro tipo apresentado pelos autores, como a própria denominação sugere, ocorre quando há o surgimento de novas concepções acerca do problema anteriormente diagnosticado, o que conduz à sua redefinição. $\mathrm{O}$ segundo mecanismo acontece com a estabilização do artefato e a melhoria do problema construído. A ocorrência desse segundo mecanismo não indica que a controvérsia tecnológica tenha sido resolvida plenamente. Entretanto, as futuras inovações que podem emergir tendem a se desenvolver a partir do modelo já conhecido, distanciando-se cada vez mais de uma possibilidade de mudança radical.

Bijker (1995) argumenta que a natureza da mudança tecnológica depende das configurações dos marcos tecnológicos em torno do artefato. Sua hipótese é a de que o caráter da mudança está diretamente relacionado ao fato da configuração sociotécnica envolver somente um ou vários marcos tecnológicos. Bem como de não existir esse marco. De acordo com esse autor, se não há um marco tecnológico dominante na construção de um novo artefato, se supõe que os atores identificaram problemas e sugeriram soluções inovadoras.

No momento da aplicação desse artefato existiria uma probabilidade relativamente mais alta de aparição de inovações radicais por fora dos marcos tecnológicos vigentes. Por um lado, se existir um marco tecnológico claramente dominante, as inovações tenderão a ser mais convencionais, seguindo o padrão de pensamento vigente. Por outro, os estímulos para as mudanças sociotécnicas mais radicais surgirão de atores sociais com uma baixa inclusão no marco tecnológico dominante. Ou seja, daqueles que estão à margem desse marco tecnológico.

Segundo Thomas (2009), o gradiente de inovação implicado em tais processos sugere a existência de estilos sociotécnicos de transformação tecnológica e inovação particulares, baseados em um conjunto de capacidades acumuladas pelos atores sociais, entre as quais se destacam as seguintes: o uso intensivo de operações de ressignificação de tecnologias, a operacionalização de conhecimentos genéricos, assim como a reutilização de habilidades, o estabelecimento de relações 
usuário/produtor/provedor específicas, o desenvolvimento de dinâmicas de melhoria de problemas e a geração de soluções não estandardizadas.

À luz dessa perspectiva, torna-se mais fácil compreender que a construção de um novo código sociotécnico está diretamente vinculada à concepção dinâmica de projetos heterogêneos, entendidos como aqueles que inter-relacionam distintas ideias, metas, valores e práticas sociais. Dessa forma, é possível compreender que atores sociais dotados de agência e amparados por domínios particulares articulam-se em arenas específicas, onde ocorrem compartilhamentos e transformações de seus projetos de vida, configurando distintos grupos sociais relevantes detentores de poder de transformação.

A inter-relação entre esses grupos sociais relevantes acontece em determinados marcos tecnológicos, por eles compartilhados ou não, os quais influenciam diretamente em suas opiniões e ações acerca de determinadas situações identificadas como problemáticas. Em meio a processos constantes de negociação, as ideias convergentes desses grupos sociais relevantes podem levar tanto a novas concepções em relação ao problema anteriormente diagnosticado quanto a um projeto heterogêneo que busca a melhoria do problema construído.

No meio rural, a perspectiva de construção de projetos heterogêneos possibilita a compreensão dos processos imbricados na busca organizada por distintos grupos de atores sociais por espaços de manobra que conduzam a melhorias nas condições de vida no campo. Os resultados do processo de modernização da agricultura, a exemplo do ocorrido no âmbito da Revolução Verde, são compreendidos como um problema construído e colocado em evidência por determinados atores sociais. Entre esses podem estar agricultores familiares, mediadores sociais vinculados a instituições públicas e não governamentais, além de gestores públicos, pesquisadores e consumidores, os quais suscitam a busca por novas estratégias de reprodução social que valorizem, para além de aspectos econômicos, as especificidades socioambientais e culturais locais.

Estudos empíricos no meio rural que analisam experiências de constituição de problemáticas e buscas por soluções, como os elaborados por Medeiros (2011), Rover (2011) e Pettenon (2014), evidenciam que em diversas arenas, grupos sociais relevantes compartilham objetivos, percepções de problemas, conhecimentos, métodos e técnicas de planejamento para a melhoria de situações problema. Nelas confrontamse, mobilizam relações sociais e transformam seus projetos de vida com o intuito de construir coletivamente um projeto de desenvolvimento que desvie da lógica puramente economicista do modelo hegemônico.

Entretanto, ainda que esse projeto possa ter como finalidade uma oposição ao estilo de agricultura capitalista suscitado pela modernização, na concepção prática desse projeto encontram-se atores sociais que não 
assumem unicamente uma ou outra forma pura de agricultura, o que confere a esse projeto uma rica heterogeneidade. Esses projetos se consolidam por meio da constante busca por estratégias de reprodução social e disputas por poder, nas transformações dinâmicas de seus projetos de vida. Dessa forma, os agricultores, principalmente familiares, podem ser ora direcionados por uma forma de agricultura, que é pautada em determinado marco sociotécnico, ora por outra forma de agricultura, que tem como base um marco sociotécnico diferente.

De acordo com seus interesses e necessidades, há desconstruções e reconstruções de distintas tecnologias que, muitas vezes, são transferidas por instituições de extensão rural e de pesquisa, as quais se aproximam mais ou menos de uma produção amplamente voltada ao mercado agroalimentar global. No entanto, é essa mesma mutualidade de influências que acaba refletindo diretamente na origem de formas de agricultura mais sustentáveis no tempo, não somente do ponto de vista socioeconômico, como também ambiental e cultural. Isso decorre do fato desses projetos ressignificarem a tecnologia na medida em que articulam formas criativas de gerir ações voltadas à melhoria de problemas condizentes com sua realidade local.

Essas articulações são catalisadoras da emergência de distintas inovações que, quando coordenadas, conformam um novo código sociotécnico que representa as coerências estabilizadoras de práticas e aprendizagens desviantes do código sociotécnico até então dominante. Essa "reação consciente" a tal código sociotécnico, materializada na coordenação de distintas iniciativas, é resultado de engajamentos de atores sociais em ações políticas, que reivindicam mudanças para além de melhorias em suas próprias vidas. Dessa forma, o vínculo entre eles, para além de interesses econômicos, traz consigo uma diversidade de conhecimentos e culturas, técnicas e práticas, assim como valores que geralmente são desenvolvidos e direcionados por determinados costumes.

\section{Á guisa de conclusão...}

O modelo de desenvolvimento rural hegemônico, profundamente enraizado nos princípios e processos da modernização da agricultura, faz parte de um padrão centrado nas dimensões econômica e tecnicista, o qual foi disseminado pelo mundo e ocasionou inúmeras transformações no campo. Tais transformações, que envolvem uma significativa diferenciação social, poluição e esgotamento de recursos naturais não renováveis, diminuição da qualidade biológica de produtos agrícolas e mercados cada vez mais concentrados, vêm conduzindo pesquisadores, mediadores sociais, consumidores e, em especial, agricultores de todos os lugares do mundo, da Europa industrializada até os recantos mais pobres 
da África ou da América Latina, a reavaliações de suas formas de produção agrícola e a reinvenções de novos projetos de desenvolvimento rural.

Para além de interesses pessoais, esses distintos atores sociais interagem conhecimentos que reforçam processos de aprendizagem, buscam melhorias nas condições de vida no campo com irradiações para o meio urbano. Suas ações e intenções compartilhadas os direcionam à arquitetura de um projeto heterogêneo que proporciona novas formações de sentido e reinvenções de práticas e técnicas, as quais, consequentemente, configuram novos códigos sociotécnicos. A intersecção entre a Perspectiva Orientada ao Ator e a Construção Social da Tecnologia se mostra profícua para a compreensão do surgimento de tais códigos.

A complementaridade dessas abordagens teóricas permite revelar que atores sociais, construtores de agência e amparados por domínios particulares, articulam-se em arenas específicas, onde ocorrem compartilhamentos e transformações de seus projetos de vida, configurando distintos grupos sociais relevantes. Essas perspectivas nos levam à constatação de que a inter-relação entre esses grupos sociais relevantes acontece em um determinado marco tecnológico por eles compartilhado, o qual influencia diretamente em suas opiniões e ações acerca de determinadas situações identificadas como problemáticas. Em meio a procedimentos constantes de negociação, as ideias convergentes desses grupos sociais relevantes podem levar tanto a novas concepções em relação ao problema anteriormente diagnosticado quanto a um projeto heterogêneo que busca a melhoria do problema construído.

Dessa forma, os novos códigos sociotécnicos que são fundamentados nas diretrizes desses projetos emergentes, na medida em que envolvem em sua constituição distintos estilos de agricultura, valorizam não somente a esfera econômica do desenvolvimento rural, como também os conhecimentos locais e a diversidade socioambiental, o que impulsiona, inclusive, rearranjos nas relações sociais e de trabalho. Essa diversidade de estilos é o que vem conferindo aos projetos heterogêneos de desenvolvimento rural a pluralidade na criação de estratégias de sobrevivência no espaço rural, com foco para as novas atividades produtivas e fontes de renda que se sustentem no decorrer dos anos.

Entretanto, apesar de seu potencial na construção de novos códigos sociotécnicos, é preciso compreender que um projeto heterogêneo é constantemente influenciado por marcos tecnológicos hegemônicos da agricultura interligada aos sistemas agroalimentares globalizados. Essa característica acaba por gerar consequências, inclusive, no que se refere à participação na construção social desses processos. Devido às regras assentidas pelo marco dominante, frequentemente se impõem 
dificuldades e obstáculos à inclusão de determinados grupos de atores sociais em processos específicos de construção sociotécnica. Isso evidencia a necessidade de valorizar a participação e organização social, o que implica focalizar as atenções às múltiplas formas de gerir, utilizar e selecionar os percursos tecnológicos locais, bem como as disputas por poder que permeiam todos esses processos.

\section{Referências bibliográficas}

BIJKER, W. E. Of Biclycles, Bakelites, and Bulbs: Toward a Theory of Sociotechnical Change, Cambridge e Londres, The MIT Press. 1995.

BOURDIEU, P. Men and machines. In: Knorr-Cetina K D and Cicourel A V (eds). 1981.

. O poder simbólico. Difel: Lisboa. 1989.

BRUUN, H.; HUKKINEN, J. Cruzando fronteras: un diálogo entre tres formas de compreender el cambio tecnológico. In: THOMAS, H.; BUCH, A. (Eds.) Actos, actores y artefactos. Sociología de la tecnología. Quilmes: Universidad Nacional de Quilmes, 2008, p. 185-216.

BRÜSEKE, F. J. A. A Modernidade Técnica. Revista Brasileira de Ciências Sociais, v. 17, n. 49, fev. de 2002.

BUNGE, M. Philosophy of science and technology: parte II: life science, social science and technology. Dordrecht: Reidel, (Treatise on basic philosophy, tomo 7). 1985.

CAPELlESSO A. J., CAZELlA A. A., FILHO A. L. S., FARLEY J., MARTINS, D. A. Economic and environmental impacts of production intensification in agriculture: comparing transgenic, conventional and agroecological maize crops. Agroecology and Sustainable Food Systems, v. 40, i. 3, 2016.

CAZELLA, A. A.; BONNAL, P.; MALUF, R. S. (Orgs.). Agricultura familiar, multifuncionalidade e desenvolvimento territorial no Brasil. Rio de Janeiro: Mauad X, NEAD, IICA, 301 p., 2009.

COTRIM, D. S. O estudo da participação na interface dos atores na arena de construção do conhecimento agroecológico. 244p. 2013. Tese (Doutorado) Programa de Pós-Graduação em Desenvolvimento Rural PGDR/UFRGS, Universidade Federal do Rio Grande do Sul, Porto Alegre, 2013.

CUPANI, A. O. Filosofia da Tecnologia: um Convite. $1^{\text {a }}$. ed. Florianópolis: Editora UFSC, v. 1, 233 p., 2013. 
DELGADO, G. C. Capital financeiro e agricultura no Brasil: 1965-1985. São Paulo, Editora da Unicamp. 1985.

FERTRIN, R. B. O Processo de Construção Social da Tecnologia: o caso do projeto habitacional Jardim dos Lírios. 418 p. Dissertação (Mestrado em Política Científica e Tecnológica) - Núcleo de Pós-Graduação do Instituto de Geociências, Universidade Estadual de Campinas: UNICAMP, 2008.

GOODMAN, D.; SORJ, B.; WILKINSON, J. Da lavoura às biotecnologias: agricultura e indústria no sistema internacional. Rio de Janeiro: Campus. 1990.

HEIDEGGER, M. Língua de tradição e língua técnica. Trad. Mário Botas, Lisboa: Passagens. 1999.

HERRERA, A. O. Desarrollo, Tecnología y Medio Ambiente. Conferência realizada durante o Primer seminario Internacional sobre Tecnologías Adecuadas en Nutrición y Vivienda - PNUMA: México. 1978. Disponível em: <http://www.agro.uncor.edu/ extrural/ AMILCAR.pdf>. Acesso: 26 abr. de 2015.

LAMARCHE, H. (Org). A agricultura familiar: comparação internacional. I. Realidade Polimorfa Campinas: UNICAMP, 336 p., 1993.

Por uma teoria da agricultura familiar. In: LAMARCHE, $\mathrm{H}$ (Coord.). Agricultura familiar: comparação internacional - do mito à realidade. Campinas, Ed. Unicamp, 1998, p. 303-336.

LONG, N. Development sociology: actor perspectives. London and New York: Routlege, 293 p., 2001.

LONG, N.; PLOEG, J. D. Heterogeneity, actor and structure: towards a reconstitution of the concept of structure. In: BOOTH, D. Rethinking social development theory, research and practice. England, Longman Scientific \& Technical, 1994, p. 62-90.

MARICONDA, P. R.; RAMOS, M. C. Transgênicos e ética: a ameaça à imparcialidade científica. Sci. stud., jun., v. 1, n. 2, 2003, p. 245-261.

MEDEIROS, M. Diversidade de saberes em situações de interface: a emergência da agricultura de base ecológica entre agricultores familiares no sul do rio grande do sul. Dissertação de Programa de Pós-Graduação em Desenvolvimento Rural, Faculdade de Ciências Econômicas da UFRGS. 2011.

MENDRAS, H. La fin des paysans, 2. ed. Paris, Actes Sud. 1984.

NIERDELE, P. A.; SCHNEIDER, S. As estratégias da transição: práticas e processos de diversificação produtiva na agricultura familiar de Salvador das Missões, RS. In: Iv Encontro de Economia Gaucha, Porto Alegre. Anais.... Porto Alegre : FEE; PUC-RS. 2008. 
NOGUEIRA, F. S. Tipos de interpretação sobre as especificidades do objeto do conhecimento na História das Ciências. Temporalidades, v. 1, 2009, p. 231-245.

PLOEG, J. D. van der. O modo de produção camponês revisitado. In: SCHNEIDER, Sergio. A diversidade da agricultura familiar. Porto Alegre: UFRGS, 2006, p. 13-56.

Camponeses e impérios alimentares: lutas por autonomia e sustentabilidade na era da globalização. Porto Alegre: UFRGS. 2008.

- Trajetórias do desenvolvimento rural: pesquisa comparativa internacional. Sociologias, v. 13, n. 27, 2011, p. 114-140.

PLOEG, J. D. van der.; HENK, R.; BRUNORI, G.; KNICKEL K.; MANNION J.; MARSDEN T.; ROEST K.; SEVILLA-GUZMÁN, E.; VENTURA, F. Rural Development: from practices and policies towards theory. Sociologia Ruralis, v. 40, n. 4, 2000, p. 391-407.

PETTENON, L. S. Dinâmicas do conhecimento e a emergência de novidades na agricultura de base ecológica no Litoral Norte do Rio Grande do Sul. Dissertação de Mestrado em Desenvolvimento Rural, Programa de PósGraduação em Desenvolvimento Rural, Universidade Federal do Rio Grande do Sul. Porto Alegre: UFRGS, 129 p., 2014.

PINCH, T; BIJKER, W. The social construction of facts and artifacts: Or how the sociology of science and the sociology of technology might benefit each other. In: BIJKER, W.; HUGHES, T; PINCH, T. The social construction of technological systems: New directions in the sociology and history of technology. Cambridge, MA: MIT Press, 1987, p. 17-50.

PINCH, T.; BIJKER, W. La construcción social de hechos y de artefactos: o acerca de cómo la sociología de la ciencia y la sociología de la tecnología pueden beneficiarse mutuamente. In: THOMAS, H.; BUCH, A. (Eds.) Actos, actores y artefactos. Sociología de la tecnología. Quilmes: Universidad Nacional de Quilmes, 2008, p. 19-62.

ROVER, O. J. Agroecologia, mercado e inovação social: o caso da Rede Ecovida de Agroecologia. Revista de Ciências Sociais UNISINOS, jan./abr., 2011.

SCHNEIDER, S. Reflexões sobre Diversidade e Diversificação: agricultura, formas familiares e desenvolvimento rural. Ruris, v. 4, n. 1, p. 85-131, mar.. Disponível em: < http://www.ufrgs.br/pgdr/ arquivos/832.pdf>. Acesso: 5 jan. de 2015.

THOMAS, H. De las tecnologías apropiadas a las tecnologías sociales: conceptos/estrategias/diseños/acciones, Conferência apresentada na $1^{a}$ Jornada sobre Tecnologías Sociales, Programa Consejo de la Demanda de Actores Sociales (PROCODAS) - MINCyT, Buenos Aires. 2009. 
THOMPSON, P. B. (2009). Philosophy of Agricultural Technology. In: Meijers, A. (Ed.) Philosophy of Technology and Engineering Sciences. Elsevier, Amsterdam, p. 1257-1273.

VIAN, C. E. F; JÚNIOR, A. M. A. (2010). Evolução histórica da indústria de máquinas agrícolas no mundo: origens e tendências. In: Sociedade Brasileira de Economia, ESALQ. Disponível em: < http://www.sober. org.br/palestra/15/1208.pdf>. Acesso: 20 fev. de 2014.

WANDERLEY, M. N. B. de. (2003). Agricultura familiar e campesinato: rupturas e continuidade. Rio de Janeiro, In: Estudos Sociedade $e$ Agricultura, n. 21, p. 42-62.

WINNER, L. (1995). Citizen Virtues in a Technological Order. In: Feenberg, A.; Hannay, A. (Eds). Technology and the Politics of Knowledge, Indiana University Press, Bloomington and Indianapolis.

MEDEIROS, Monique, Adinor José Capellesso, Ademir Antonio Cazella e Geneviève Cortes. O surgimento de novos códigos sociotécnicos na construção de projetos desviantes de desenvolvimento rural. Estudos Sociedade e Agricultura, junho de 2017, vol. 25, n. 2, p. 406-429, ISSN 25267752.

Resumo: (O surgimento de novos códigos sociotécnicos na construção de projetos desviantes de desenvolvimento rural). Ao viabilizar a produção em maior escala, as tecnologias modernas incorporadas no campo passaram a ser fator indispensável para que uma parcela de agricultores mantenha-se nas cadeias competitivas. Se, por um lado, grupos de agricultores não encontram alternativas para melhoria na condição de vida nesse padrão tecnológico, por outro, são crescentes as preocupações acerca das consequências negativas desse processo. Para enfrentar essa situação, distintos atores sociais constroem novos códigos sociotécnicos que desviam do modelo hegemônico de desenvolvimento. Com a atenção direcionada a esses cenários, este artigo objetiva elaborar uma base teórica para a compreensão desses novos códigos. Demonstra-se que a possibilidade de contemplar os preceitos econômicos, sociais e ambientais da sustentabilidade em projetos heterogêneos de desenvolvimento rural 
passa, principalmente, pela adequação das tecnologias aos contextos sociais.

Palavras-chave: atores sociais, projetos heterogêneos, desenvolvimento rural, mudanças tecnológicas.

Abstract: (The emergence of new socio-technical codes in the construction of deviant projects of rural development). Enabling production on a larger scale, modern technologies embedded in the countryside have become an indispensable factor for farmers to remain in competitive chains. If, on the one hand, groups of farmers do not find alternatives to improve their living conditions within this technological standard, on the other, there are increasing concerns about the negative consequences of these processes. In the face of these contradictions, different social actors, creatively, are building new socio-technical codes that deviate from the hegemonic model of development. With attention directed to these scenarios, this article aims to provide bases for understanding these codes. And, in summary, it demonstrates that the possibility of incorporating economic, social and environmental principles of sustainability in heterogeneous projects of rural development involves, mainly, the adaptation of technologies to social contexts.

Keywords: social actors, heterogeneous projects, rural development, technological changes.

Recebido em fevereiro de 2016.

Aceito em abril de 2017. 